\title{
Acute Kidney Injury with Epstein Barr Virus-Associated Hemophagocytic Syndrome
}

\author{
Ryo Ishida ${ }^{1,2}{ }^{*}$, Kazumi Komaki ${ }^{1,2}$, Tetsuro Kusaba ${ }^{1,2}$, Tsuneyuki Nakanouchi ${ }^{1}$ \\ ${ }^{1}$ Japanese Red Cross Kyoto Daiichi Hospital, Kyoto, Japan \\ ${ }^{2}$ Division of Nephrology, Department of Medicine, Kyoto Prefecture University of Medicine, Kyoto, Japan \\ Email: "ryoishi2006@yahoo.co.jp
}

Received 16 June 2016; accepted 22 July 2016; published 25 July 2016

Copyright (C) 2016 by authors and Scientific Research Publishing Inc.

This work is licensed under the Creative Commons Attribution International License (CC BY). http://creativecommons.org/licenses/by/4.0/

(c) (i) Open Access

\begin{abstract}
A 59-year-old man, who was treated for schizophrenia and psoriasis vulgaris with risperidone and cyclosporine, presented with high fever and myalgia. Those did not respond to treatment for neuroleptic malignant syndrome for two weeks, and multiple organ dysfunction developed, so he was admitted to our hospital, but died two days later. Autopsy detected the hemophagocytosis, Epstein Barr Virus (EBV)-reactivated cells, and the absence of glomerulonephritis and interstitial tubulitis. We considered that hemophagocytic syndrome (HPS) and myalgia were caused by reactivated EBV and the viremia under immunosuppression, and renal failure was caused by sepsis-like state by cytokine storm of HPS.
\end{abstract}

\section{Keywords}

Hemophagocytic Syndrome, Epstein Barr Virus, Acute Kidney Injury

\section{Introduction}

Hemophagocytic syndrome (HPS) is a rare disorder of the immune system that is synonymous with macrophage activation syndrome [1]. Natural killer (NK)/T cells that, for hereditary or acquired reasons, are unable to lyse target cells, such as infected or malignant cells, proliferate and release a large amount of interferon- $\gamma$. This induces the proliferation of macrophages, invasion into the liver, spleen, and lymph nodes, and the release of further inflammatory cytokines including TNF- $\alpha$ [2]. HPS causes a cytokine storm.

HPS may be caused by infections, malignancies, or rheumatic diseases [3]. Infection accounts for $50 \%$ of all cases of HPS, and viral infection for 69\% of all cases of infection-related HPS. Moreover, Epstein Barr Virus 
(EBV) accounts for $43 \%$ of viral infections [4]. EBV-associated HPS is an EBV-lymphoproliferative disorder (EBV-LPD) of NK/T cells [5]-[7]. EBV typically invades B cells via the B cell-specific CD21 antigen and infects latently; however, EBV infects NK/T cells incidentally, resulting in HPS as well as infectious mononucleosis [5] [8] [9].

We herein report a case of EBV-associated HPS receiving immunosuppressive therapy. We also discuss the pathophysiology of acute kidney injury (AKI) and the clinical symptoms preceding HPS.

\section{Case Report}

A 59-year-old man, who had been treated for schizophrenia and psoriasis vulgaris with the oral administration of $1 \mathrm{mg}$ risperidone and $300 \mathrm{mg}$ cyclosporine, presented to another hospital with high fever and myalgia. He was diagnosed with neuroleptic malignant syndrome, and was admitted to the hospital for treatment; however, these symptoms persisted for more than two weeks. Moreover, renal and liver dysfunction developed; therefore, he was admitted to our hospital. A physical examination revealed a body temperature of $38.8^{\circ} \mathrm{C}$, pulse rate of 110 beats per minute, respiratory rate of 30 breaths per minute, and blood pressure of 80/55 mmHg. He was drowsy and had leg edema. Laboratory data showed pancytopenia, metabolic acidosis, and liver and kidney dysfunction (Table 1). Urinary findings were mild hematuria and proteinuria (Table 1). Chest and abdominal computed tomography (CT) showed that there were no obvious inflammatory findings, except for mild swelling of the superficial lymph nodes (Figure 1). In order to treat circulatory failure and multiple organ dysfunction, he underwent continuous hemodiafiltration and endotoxin adsorption using catecholamine and antibiotics under artificial ventilation. In spite of intensive care, he died after two days. Autopsy showed that hemophagocytosis was present in bone marrow (Figure 2(a)). Macrophages had infiltrated the lymph nodes and liver (Figures 2(b)-(e)), and EBV-reactivated cells were detected in bone marrow, the lymph nodes, and spleen by staining for the

Table 1. Laboratory data on admission.

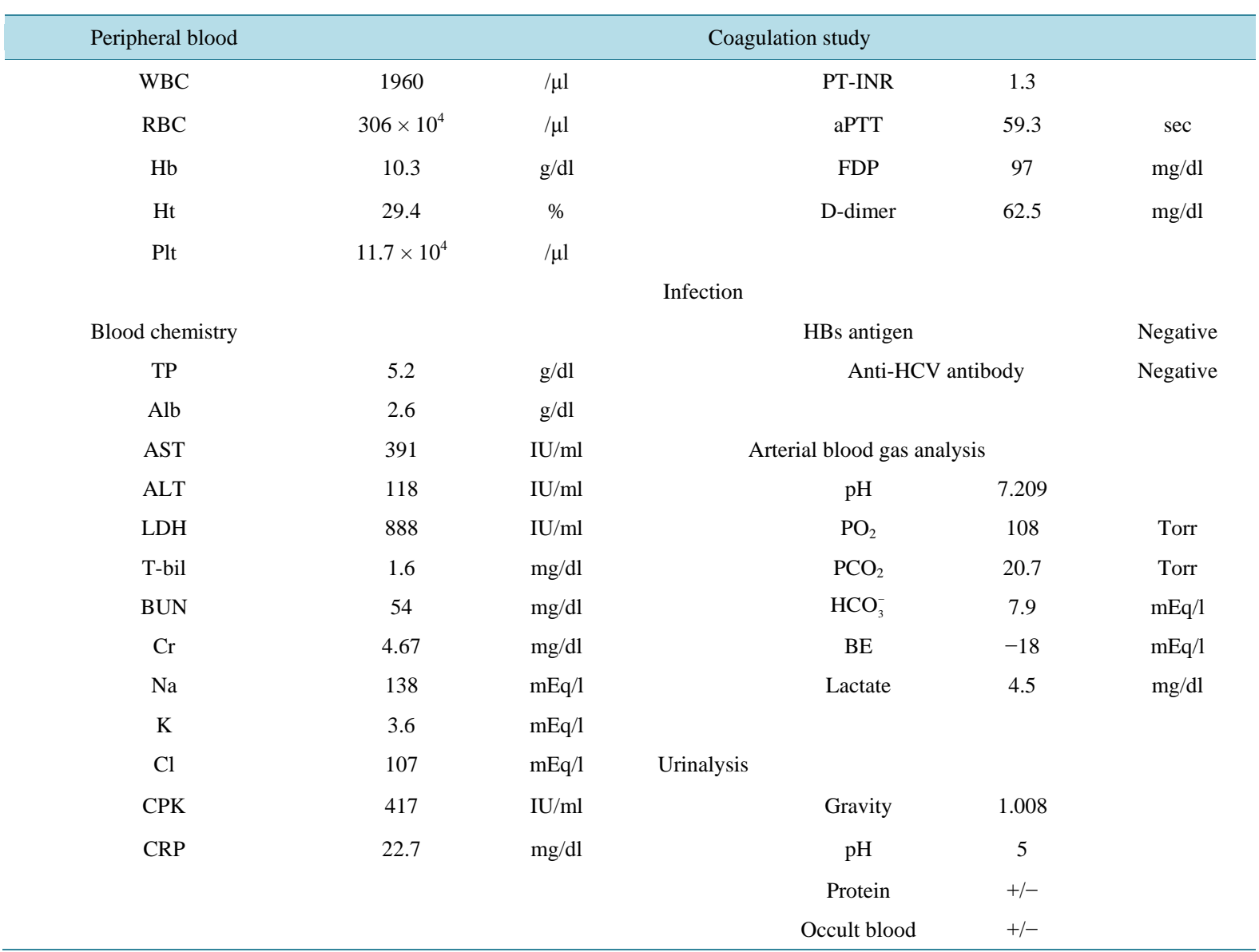




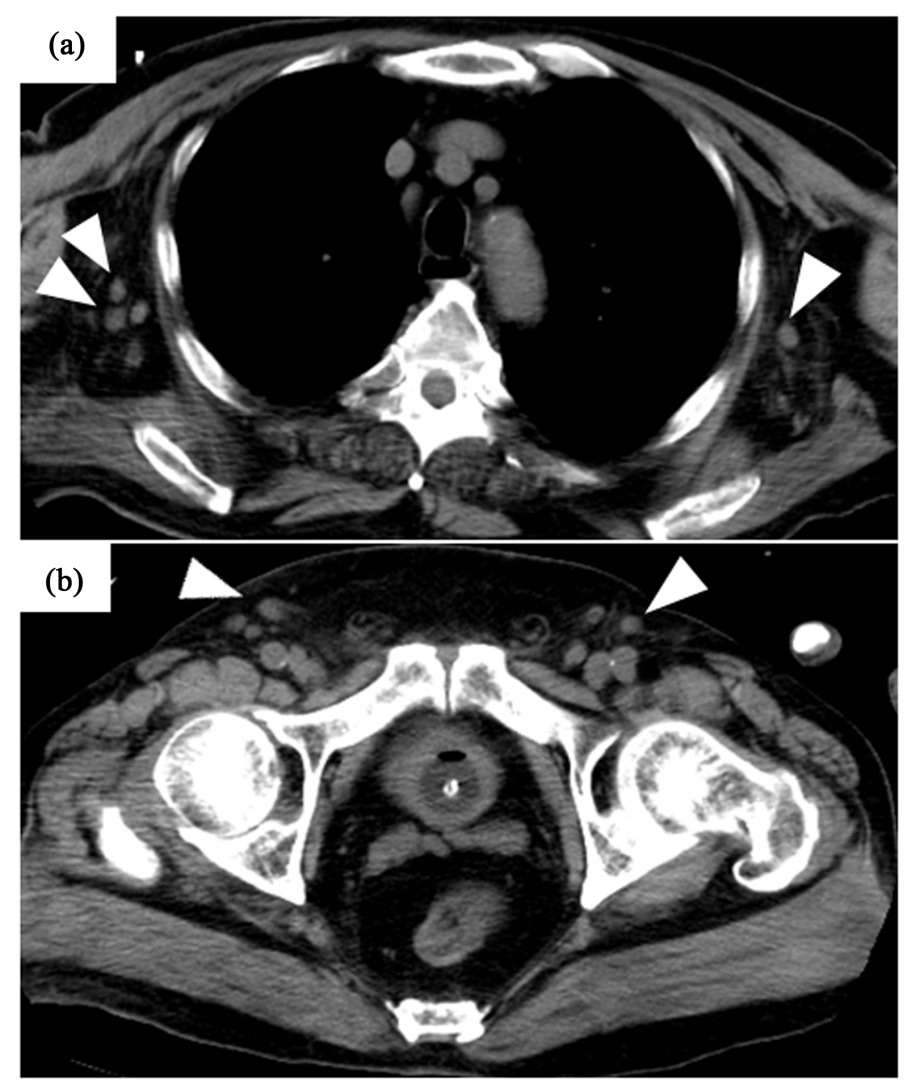

Figure 1. Findings for chest and abdominal CT on admission. (a) Chest CT revealed mildly swollen axillary lymph nodes (arrowhead); (b) Abdominal CT showed mildly swollen inguinal lymph nodes (arrowhead).
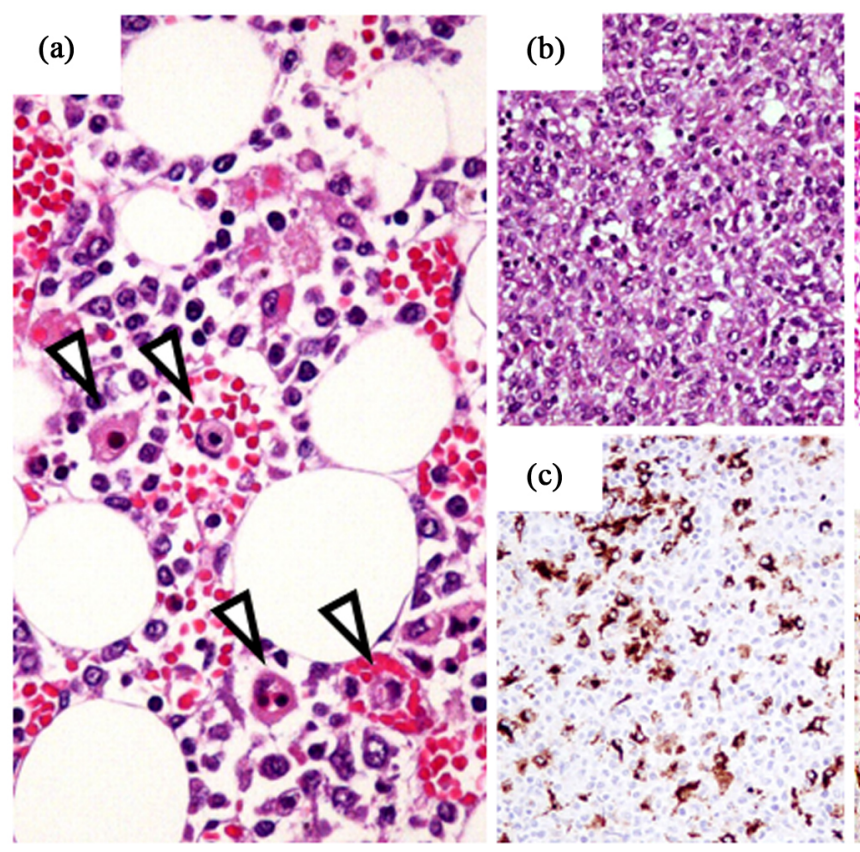

(D)
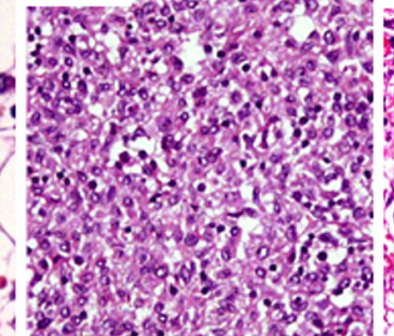

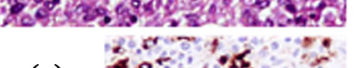

(c) \& o


(g)

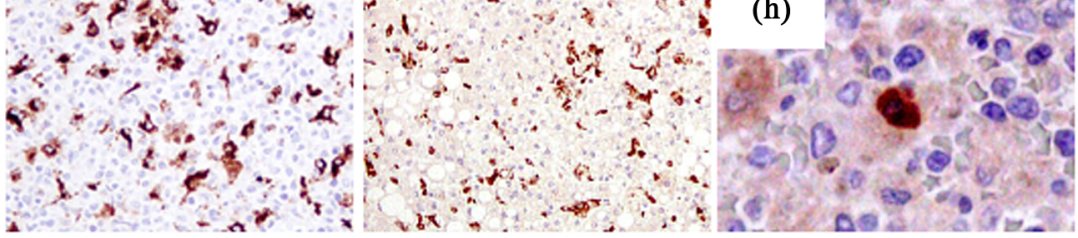

Figure 2. Findings for bone marrow, lymph nodes, liver and spleen in autopsy samples. (a) Hemophagocytosis was detected in bone marrow (HE stain, arrowhead). (b) (c) Macrophages infiltrated the lymph nodes ((b) HE stain, (c) CD68 stain). (d) (e) Macrophages infiltrated the liver ((d) HE stain, (e) CD68 stain). (f) The EBV-ZEBRA stain shows that EBV-reactivated cells were present in bone marrow (arrowhead). (g) (h) These cells were also detected in the lymph nodes and spleen. 

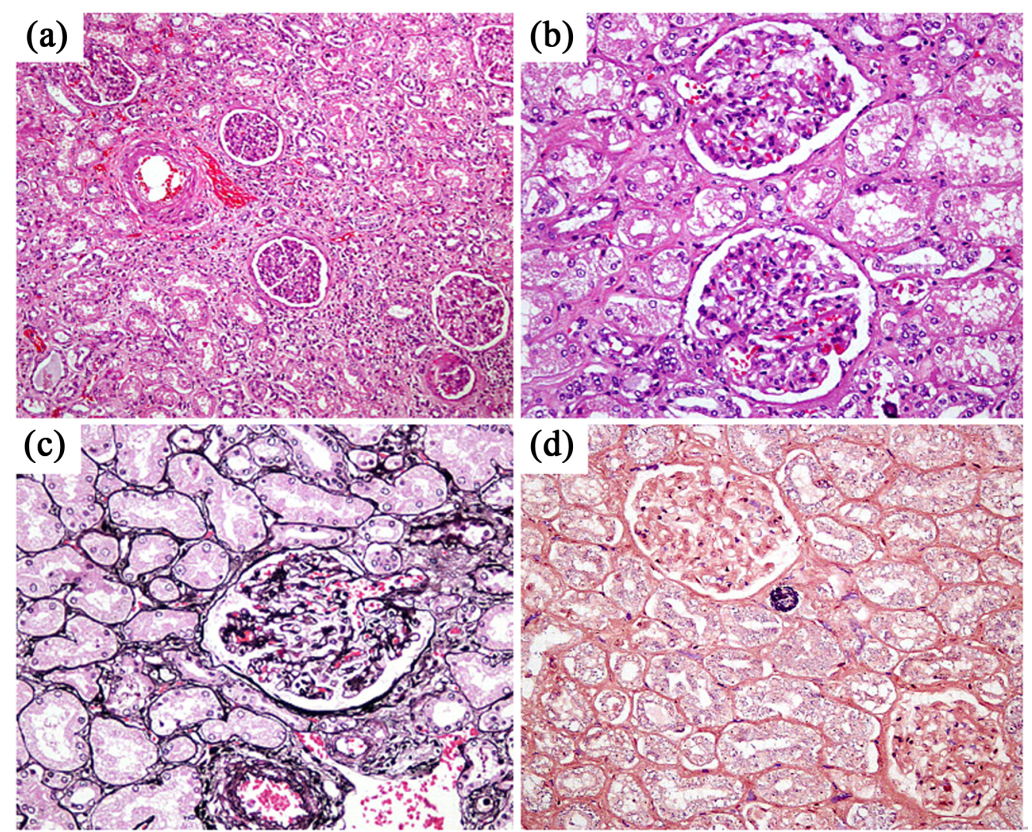

Figure 3. Findings for glomeruli and tubulointerstitium in renal autopsy samples. (a) (b) (c) There was no obvious glomerulonephritis or interstitial tubulitis in renal histology ((a) (b) Periodic acid-Schiff stain, (c) Periodic Schiff-Methenamine Silver stain). (d) There was no obvious fibrosis in renal histology (phosphotungstic acid hematoxylin stain).

EBV-ZEBRA protein, which is an EBV immediate-early transcription factor that triggers the switch from latent to lytic infection (Figures 2(f)-(h)). Despite serological renal dysfunction, glomerulonephritis, interstitial tubulitis, and fibrosis were not present in renal histology (Figures 3(a)-(d)).

\section{Discussion}

HPS often has a very poor prognosis with acute progression and a mortality rate of $41 \%$ [4]; therefore, it is important to consider the preceding symptoms for an earlier diagnosis and treatment. In our case, HPS developed due to the reactivation of EBV preceded by myalgia under immunosuppressive therapy. In addition, despite clinical renal dysfunction, autopsy showed that there was no obvious renal injury. We herein discuss myalgia preceding HPS and AKI without obvious histological injury.

Common symptoms in HPS include high fever that does not respond to antibiotics, liver dysfunction, hepatosplenomegaly, and coagulopathy, which occur with HPS, but do not precede it [1]. Myalgia was detected in the present case, and had not previously been identified as a symptom of HPS. On the other hand, myalgia is a common symptom of EBV infection, and rhabdomyolysis associated with EBV infection has been reported [10] [11]. In the development of EBV-associated HPS, latent EBV in B cells is reactivated under immunosuppression, proliferates, and infects NK/T cells through the viremia of EBV. Therefore, myalgia may be a symptom of the viremia of reactivated EBV preceding HPS; however, it was initially considered to be induced by neuroleptic malignant syndrome because of psychometric medical treatment.

AKI is the most frequent renal manifestation, accounting for $62 \%$ of renal involvement cases in HPS [12]. HPS-induced AKI has been attributed to various pathophysiologies including acute tubular necrosis and glomerulopathy such as minimal change disease, focal segmental glomerulosclerosis, and thrombotic microangiopathy [4]; however, renal histology revealed that there was no obvious damage to the glomerulus, interstitium, or tubules in our case. Concerning the cytokine storm including TNF- $\alpha$ in HPS, AKI in our case may resemble sepsis-induced AKI.

Sepsis is characterized by an excessive inflammatory response to infection through the interaction of biochemical mediators and amplification cascades, and induces the release of inflammatory cytokines such as TNF- $\alpha$ [13] [14]. Sepsis-induced AKI is known as septic AKI, in which efferent arteriolar vasodilatation de- 
creases glomerular filtration pressure and urine production by several cytokines without obvious damage in the histology [15] [16]. Therefore, the pathophysiology of no obvious histological damage and the cytokine storm in HPS appear to support the hypothesis of a similarity with septic AKI and HPS-induced AKI in our case.

\section{Conclusion}

In conclusion, HPS-induced AKI in our case may have resembled septic AKI due to the cytokine storm. In addition, myalgia under immunosuppressive therapy and psychometric medical treatment may be due to the viremia of reactivated EBV as well as neuroleptic malignant syndrome. Since HPS has a severely poor prognosis with acute progression, it is important to consider the preceding symptoms for an earlier diagnosis and treatment.

\section{References}

[1] Imashuku, S. (2002) Clinical Features and Treatment Strategies of Epstein-Barr Virus-Associated Hemophagocytic Lymphohistiocytosis. Critical Reviews in Oncology/Hematology, 44, 259-272.

http://dx.doi.org/10.1016/S1040-8428(02)00117-8

[2] Fujiwara, F., Hibi, S. and Imashuku, S. (1993) Hypercytokinemia in Hemophagocytic Syndrome. The American Journal of Pediatric Hematology/Oncology, 15, 92-98. http://dx.doi.org/10.1097/00043426-199302000-00012

[3] Madkaikar, M., Shabrish, S. and Desai, M. (2016) Current Updates on Classification, Diagnosis and Treatment of Hemophagocytic Lymphohistiocytosis (HLH). Indian Journal of Pediatrics, 83, 434-443. http://dx.doi.org/10.1007/s12098-016-2037-y

[4] Filippone, E.J. and Farber, J.L. (2016) Hemophagocytic Lymphohistiocytosis: An Update for Nephrologists. International Urology and Nephrology. [Epub Ahead of Print] http://dx.doi.org/10.1007/s11255-016-1294-z

[5] Grywalska, E., Markowicz, J., Grabarczyk, P., Pasiarski, M. and Rolinski, J. (2013) Epstein-Barr Virus-Associated Lymphoproliferative Disorders. Postępy Higieny i Medycyny Doświadczalnej (Online), 67, 481-490. http://dx.doi.org/10.5604/17322693.1050999

[6] Kawa, K. (2002) Diagnosis and Treatment of Chronic Active EBV Infection. Uirusu, 52, 257-260. http://dx.doi.org/10.2222/jsv.52.257

[7] Kawa, K. (2000) Epstein-Barr Virus-Associated Diseases in Humans. International Journal of Hematology, 71, 108117.

[8] Fingeroth, J.D., Weis, J.J., Tedder, T.F., Strominger, J.L., Biro, P.A. and Fearon, D.T. (1984) Epstein-Barr Virus Receptor of Human B Lymphocytes Is the C3d Receptor CR2. Proceedings of the National Academy of Sciences USA, 81, 4510-4514. http://dx.doi.org/10.1073/pnas.81.14.4510

[9] Anagnostopoulos, I., Hummel, M, Kreschel, C. and Stein, H. (1995) Morphology, Immunophenotype, and Distribution of Latently and/or Productively Epstein-Barr Virus-Infected Cells in Acute Infectious Mononucleosis: Implications for The Interindividual Infection Route of Epstein-Barr Virus. Blood, 85, 744-750.

[10] Osamah, H., Finkelstein, R. and Brook, J.G. (1995) Rhabdomyolysis Complicating Acute Epstein-Barr Virus Infection. Infection, 23, 119-120. http://dx.doi.org/10.1007/BF01833879

[11] Friedman, B.I. and Libby, R. (1986) Epstein-Barr Virus Infection Associated with Rhabdomyolysis and Acute Renal Failure. Clinical Pediatrics (Phila), 25, 228-229. http://dx.doi.org/10.1177/000992288602500412

[12] Aulagnon, F., Lapidus, N., Canet, E., et al. (2015) Acute Kidney Injury in Adults with Hemophagocytic Lymphohistiocytosis. American Journal of Kidney Diseases, 65, 851-859. http://dx.doi.org/10.1053/j.ajkd.2014.10.012

[13] Bone, R.C., Balk, R.A., Cerra, F.B., et al. (1992) Definitions for Sepsis and Organ Failure and Guidelines for the Use of Innovative Therapies in Sepsis. The ACCP/SCCM Consensus Conference Committee. American College of Chest Physicians/Society of Critical Care Medicine. Chest, 101, 1644-1655. http://dx.doi.org/10.1378/chest.101.6.1644

[14] Marshall, J.C., Vincent, J.L., Fink, M.P., et al. (2003) Measures, Markers, and Mediators: Toward a Staging System for Clinical Sepsis. A Report of the Fifth Toronto Sepsis Roundtable, Toronto, Ontario, Canada, October 25-26, 2000. Critical Care Medicine, 31, 1560-1567. http://dx.doi.org/10.1097/01.CCM.0000065186.67848.3A

[15] Schrier, R.W. and Wang, W. (2004) Acute Renal Failure and Sepsis. New England Journal of Medicine, 351, 159-169. http://dx.doi.org/10.1056/NEJMra032401

[16] Lipcsey, M. and Bellomo, R. (2011) Septic Acute Kidney Injury: Hemodynamic Syndrome, Inflammatory Disorder, or Both? Critical Care, 15, 1008. http://dx.doi.org/10.1186/cc10525 


\section{Submit or recommend next manuscript to SCIRP and we will provide best service for you:}

Accepting pre-submission inquiries through Email, Facebook, LinkedIn, Twitter, etc.

A wide selection of journals (inclusive of 9 subjects, more than 200 journals)

Providing 24-hour high-quality service

User-friendly online submission system

Fair and swift peer-review system

Efficient typesetting and proofreading procedure

Display of the result of downloads and visits, as well as the number of cited articles

Maximum dissemination of your research work

Submit your manuscript at: http://papersubmission.scirp.org/ 